\title{
The Difference in Thyroid Stimulating Hormone Levels between Differentiated Carcinoma and Benign Enlargement
}

\author{
Bambang Udji Djoko Rianto ${ }^{1 \odot}$ Anton Sony Wibowo ${ }^{1}$ Camelia Herdini ${ }^{1}$ \\ ${ }^{1}$ Ear Nose Throat Head and Head Neck Surgery Department, Faculty \\ of Medicine, Universitas Gadjah Mada/Dr. Sardjito GH Yogyakarta, \\ Indonesia \\ Address for correspondence Bambang Udji Djoko Rianto, MSc, PhD, \\ Nose Throat Head and Head Neck Surgery Department Faculty of \\ Medicine, Universitas Gadjah Mada/Dr. Sardjito GH, Jalan Farmako \\ Yogyakarta, Indonesia (e-mail: djoriant@ugm.ac.id).
}

Int Arch Otorhinolaryngol 2020;24:e73-e79.

\begin{abstract}
Introduction Papillary and follicular thyroid carcinoma are common head and neck cancers. This cancer expresses a thyroid stimulating hormone (TSH) receptor that plays a role as a cancer stimulant substance. This hormone has a diagnostic value in the management of thyroid carcinoma.

Objective The present study aimed to determine the difference in TSH levels between differentiated thyroid carcinoma and benign thyroid enlargement.

Methods The present research design was a case-control study. The subjects were patients with thyroid enlargement who underwent thyroidectomies at the Dr. Sardjito General Hospital, Yogyakarta, Indonesia. Thyroid stimulating hormone levels were measured before the thyroidectomies. The inclusion criteria for the case group were: 1) differentiated thyroid carcinoma, and 2) complete data; while the inclusion criteria for the control group were: 1 ) benign thyroid enlargement, and 2) complete data. The exclusion criteria for both groups were: 1) patients suffering from thyroid hormone disorders requiring therapy before thyroidectomy surgery, 2) patients receiving thyroid suppression therapy before the thyroidectomy was performed, and 3) patients suffering from severe chronic diseases such as renal insufficiency, and severe liver disease.

Keywords

- thyroid stimulating hormone

- thyroid adenoma

- thyroid carcinoma

- thyrotropin

- thyroid neoplasms

Results There were 40 post-thyroidectomy case group patients and 40 post-thyroidectomy control group patients. There were statistically significant differences in TSH levels between the groups with differentiated thyroid carcinoma and benign thyroid enlargement $(p=0.001$; odds ratio $[\mathrm{OR}]=8.42$; 95\% confidence interval $[\mathrm{Cl}]: 3.19-36.50)$.

Conclusion Based on these results, it can be concluded that there were significant differences in TSH levels between the groups with differentiated thyroid carcinoma and benign thyroid enlargement.
\end{abstract}

\section{Introduction}

Thyroid stimulating hormone (TSH) has a crucial role for the growth and the progression of differentiated carcinoma in the thyroid. ${ }^{1,2}$ Considered a potentially treatable but commonly fatal cancer with increasing incidence due to its slow- acting nature and tendency for metastasis, patients often present late for treatment, resulting in poor outcomes. Measurements of receptor levels and their effect on signaling pathways have been shown to be effective for accurate diagnosis, but prognoses remain challenging due to many factors. Although TSH levels may be normal, the malignancy received

March 26, 2018

accepted

May 8, 2019
DOI https://doi.org/

10.1055/s-0039-1692406. ISSN $1809-9777$.
Copyright $(2020$ by Thieme Revinter

Publicações Ltda, Rio de Janeiro, Brazil
License terms

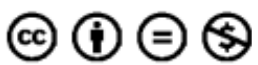


risk of thyroid nodules will increase if TSH levels are above the average range of the population. ${ }^{3}$

Thyroid stimulating hormone receptors (TSHRs) are essential in the metabolism of the thyroid hormone, and control the functions and growth of the main thyroid cells. A number of thyroid diseases, most notably hyperthyroidism, are associated with mutations in the TSHRs. Recent research has found that while genetic and epigenetic alterations in the TSHRs are not the direct cause of carcinogenesis, they significantly influence and contribute to tumor growth, which involves several oncogenes. ${ }^{4,5}$

A study by Fiore et al confirmed the link between TSH and thyroid cancer, and discussed the relevant research of the recent decades, which included subjects diagnosed on cytology in a large series of patients submitted to fine needle aspiration biopsy of thyroid nodules, after validating cytology in a series of 3,406 nodules from 3,004 patients who underwent surgery. The relationship between serum TSH levels and risk of papillary thyroid cancer (PTC) was further analyzed in 10,178 patients with a clinical diagnosis of nodular goitre and with a cytological diagnosis of PTC $(n=497)$ and of benign nodular thyroid disease $(n=9,681)$. Serum TSH was significantly higher in PTC (median: $1.10 \mathrm{mIU} / \mathrm{L}$; interquartile range (IR): 0.70-1.70 $\mathrm{mIU} / \mathrm{L})$ than in patients with benign nodular thyroid disease (median: $0.70 \mathrm{mIU} / \mathrm{L}$; IR: $0.30-1.20 \mathrm{mIU} / \mathrm{L}$ ). The frequency of PTC was directly correlated to serum TSH levels, being the lowest in patients with subnormal TSH values (51 of 2,$024 ; 2.5 \%)$, and the highest in patients with TSH values between 1.6 and $3.4 \mathrm{mIU} / \mathrm{L}$ (152 of 1,$665 ; 9.1 \%$ ). This observation is relevant on clinical grounds to define the risk of PTC in patients with nodular thyroid disease. Thyroid stimulating hormone concentrations were significantly higher in patients with differentiated thyroid cancer $(2.08 \pm 2.1 \mathrm{mIU} / \mathrm{L})$ than in patients with benign thyroid disease $(1.36 \pm 1.62 \mathrm{mIU} / \mathrm{L})$. There was a direct relationship between increment of tumor size and increased TSH levels. $^{6}$

False negative diagnoses and conflicting reports have contributed to the debate about thyroid oncogenesis and the association of thyroid disease with TSH levels. One study of 41 patients with thyroid gland disorders, whose age ranged from 14 to 80 years old, and with controls aged between 29 and 66 years old, found that there was no significant difference between the TSH concentration and free T4 (fT4) values between the control and the thyroid disorder groups $(p>0.05) .^{7}$ The insignificant results may have been due to the small sample size or to other environmental factors.

Clinical thyroid diseases can be classified as euthyroid, hypothyroid, and hyperthyroid, according to the functional status. Thyroid functions are normal in a considerable number of patients with thyroid cancer. Measurement of highly sensitive thyrotropin (TSH) in serum plays the main role in the diagnosis of thyroid dysfunctions and has a predictive value for thyroid malignancies. While there are many factors that contribute to the carcinogenesis of the thyroid gland, TSH is considered a key cancer growth factor for thyroid cancer. $^{8,9}$
The impact of vascular invasion on the prognosis is still a matter of debate, as some researchers further subdivide the diagnosis into angioinvasive and nonangioinvasive tumors. Age $>45$ years old, gender, extrathyroid invasion, greater tumor size, and the presence of distant metastasis at presentation are recognized risk factors for a poorer prognosis. Nevertheless, there is controversy concerning the prognostic significance of these risk factors, which could influence the treatment decision-making, especially for patients with follicular thyroid carcinoma (FTC). ${ }^{10,11}$

Palpable thyroid nodules are a common disorder detected in between 4 and $7 \%$ of adults in the general population, and in between 19 and $67 \%$ of the patients who undergo highresolution ultrasound. In contrast, thyroid cancer is rare. However, in most cases, thyroid carcinoma presents clinically as a nodule (solitary or in a multinodular gland) that is indistinguishable from benign neoplasia. The challenge for clinicians, therefore, is to distinguish malignant (5-10\%) from benign thyroid nodules, because some cases of welldifferentiated thyroid cancer are significantly more aggressive than others, making it difficult to predict the treatment course of a patient. ${ }^{10-13}$

In one community population-based study, a total of 615 patients participated, with a mean age of $55.9 \pm 14.7$ years old, and 544 (88.5\%) were female. The median TSH values were 1.48 and $1.55 \mu \mathrm{U} / \mathrm{mL}$ in males and females, respectively. A total of 160 patients underwent thyroidectomy, and the final diagnoses were malignant in 47 (29.4\%) patients. The TSH levels were higher in patients with malignant tumors than in those with benign nodules in both TSH assays: 2.25 versus $1.50 \mu \mathrm{U} / \mathrm{mL}(p=0.04)$. Additional analyses using TSH levels as a categorical variable, defined by receiver operating characteristic (ROC) curve analysis, showed that the risk of malignancy was $\sim 3$-fold higher in patients with TSH levels $\geq 2.26 \mu \mathrm{U} / \mathrm{mL}$ than in patients with lower TSH levels $(p=0.01)^{13}$

Thyroid carcinoma stems from the two types of cells found in the thyroid gland. Follicular cells developing from the endodermal can develop into papillary and follicular carcinomas. Cells derived from neuroendocrine-derived calcitonin-producing $C$ cells can progress to medullary thyroid carcinoma. Thyroid lymphoma develops from lymphoid tissue found in the thyroid tissue, while thyroid sarcoma originates from the connective tissue contained in the thyroid. $^{14}$

Although there are still some differences in views from previous studies about the exact mechanism, TSH is clearly involved in the process of carcinogenesis. Recent research concluded that TSHR stimulation is linked to an increased incidence of cancer and aggressiveness of thyroid carcinoma. Mutations in TSHR will affect the cyclic adenosine monophosphate (cAMP) activation pathway via transcription factors, including $G$ alpha sigma (G $\alpha s$ ). The fact that higher levels of TSH are significantly associated with an increased risk of malignancy is strong evidence that TSHR stimulation is linked to thyroid carcinoma. ${ }^{15}$ Differentiated thyroid carcinomas express TSHR. Although oncogenes and other growth factors are also involved in the growth and development of 
thyroid carcinoma, TSH is a main stimulant for cancer growth. ${ }^{16}$

While many thyroid tumors grow unnoticed until forming nodules or enlarged lobes, the measurement of this growth factor hormone can provide a crucial contribution to predict the potential course from benign enlargement into the differentiated carcinoma. To develop more effective treatments, it is necessary to study the difference in TSH levels between differentiated thyroid carcinoma and benign thyroid enlargement.

\section{Objective}

The present study aimed to determine the difference in TSH levels between differentiated thyroid carcinoma and benign thyroid enlargement.

\section{Methods}

The present research was an analytic observational hospitalbased study with a case control design. The present study was conducted after receiving approval from the Medical and Health Research Ethics Committee (MHREC) under the reference number KE/FK/0766/EF/2017. The present study was conducted in the Department of Otorhinolaryngology Head and Neck Surgery between January 2015 and December 2016. The histopathologic examinations were conducted at the Anatomic Pathology Department, and the TSH level examinations were conducted at the Clinical Pathology Laboratory.

The sample subjects were patients with thyroid enlargement who underwent thyroidectomies. The sample size was calculated using hospital-based study sample size formulation for case control study or hypothesis testing for two proportions, with error type I $(\alpha) 5 \%$ one-tailed hypothesis, and error type II $(\beta)$ 20\%. ${ }^{17}$

The recommended sample size was 80 samples, with 40 subjects in both case and control groups. The present study started with identification of differentiated thyroid carcinoma as an outcome in the case group $(n=40)$, and patients with benign thyroid enlargement as a control group $(n=40)$; then, we matched the histopathologic characteristics results and TSH levels that had been measured before the thyroidectomies.

The inclusion criteria of the case group were: 1) differentiated thyroid carcinoma, and 2) complete data; while for the control group the inclusion criteria were: 1) benign thyroid enlargement, and 2) complete data. The exclusion criteria for both groups were: 1) patients suffering from thyroid hormone disorders requiring therapy before the thyroidectomy surgery, 2) patients receiving thyroid suppression therapy before the thyroidectomy was performed, and 3) patients who suffered from severe chronic diseases, such as renal insufficiency, and severe liver disease.

\section{Statistical Analysis}

The TSH levels and histopathological results were analyzed among and between groups using t-tests and multivariate analyses.

\section{Results}

The total number of sample subjects were 80 patients. Final pathology results for differentiated thyroid carcinoma (papillary and follicular thyroid carcinoma) were 40 subjects. The other 40 subjects were diagnosed for benign thyroid nodule (benign colloid nodule and adenoma) based on pathology examination.

\section{Discussion}

The pathogenesis of thyroid carcinoma is very complex, and is closely related to the heredity of the patient, to the environment, and to endocrine levels, and, additionally, to exposure to radioactive substances. ${ }^{18}$ One retrospective study from January 1999 to December 2015 with 533 enrolled patients found that $159(29.8 \%)$ patients were diagnosed with PTC, of which 38 (35.5\%) had Hashimoto thyroiditis (HT). More patients with HT were female, and patients with HT, Graves disease, and thyroid nodules with higher TSH levels had a higher incidence of PTC. There was a trend that a higher serum TSH level was associated with a greater risk of thyroid cancer. ${ }^{19}$

Thyroid cancer is a type of malignant endocrine system tumor with an increasing incidence rate, which consists of four different pathological types: PTC, medullary carcinoma, follicular carcinoma, and undifferentiated carcinoma. Approximately between 60 and $89 \%$ of the thyroid cancers are of the PTC type, which is highly differentiated and often occurs in children or female patients aged between 20 and 50 years old. ${ }^{20}$

This hospital-based study found that female subjects were more frequent than males for all patients with thyroid enlargement (-Table 1). There were 60 (75.0\%) females, and 20 (25.0\%) males. Based on the $x^{2}$ test, there was no significant differences between gender between groups $(p=0.95)$. Another study found that malignant nodules were significantly more frequent in males, had compression symptoms more commonly, were more likely palpable and with lymphopathy, and were associated with higher TSH concentrations. $^{21}$

The mean difference in this hospital population-based study for fT4 levels between malignant and benign groups was tested with independent sample t-tests (-Table 2 ).

Table 1 Characteristics of the subjects

\begin{tabular}{|c|c|c|c|c|}
\hline \multirow[t]{2}{*}{ Variable } & $\begin{array}{l}\text { Cases } \\
\text { (malignant) }\end{array}$ & $\begin{array}{l}\text { Control } \\
\text { (benign) }\end{array}$ & Total & \multirow[t]{2}{*}{$p$-value } \\
\hline & $n(\%)$ & $n(\%)$ & $n(\%)$ & \\
\hline $\begin{array}{l}\text { Gender } \\
\text { Male } \\
\text { Female }\end{array}$ & $\begin{array}{l}15(37.5) \\
25(62.5)\end{array}$ & $\begin{array}{l}15(37.5) \\
25(62.5)\end{array}$ & $\begin{array}{l}30(37.5) \\
50(62.5)\end{array}$ & 1.000 \\
\hline $\begin{array}{l}\text { Age } \\
<45 \text { years old } \\
\geq 45 \text { years old }\end{array}$ & $\begin{array}{l}14(35) \\
26(65) \\
\end{array}$ & $\begin{array}{l}18(45) \\
22(55) \\
\end{array}$ & $\begin{array}{l}32(40) \\
48(60)\end{array}$ & 0.361 \\
\hline $\begin{array}{l}\text { Nodule } \\
\text { Uninodular } \\
\text { Multinodular } \\
\text { Size }\left(\mathrm{cm}^{3}\right)\end{array}$ & $\begin{array}{l}30(75) \\
10(25) \\
3.78 \pm \\
2.32\end{array}$ & $\begin{array}{l}19(47.5) \\
21(52.5) \\
5.12 \pm \\
3.89\end{array}$ & $\begin{array}{l}49(61.25) \\
31(38.75)\end{array}$ & $\begin{array}{l}0.012 \\
0.065\end{array}$ \\
\hline
\end{tabular}


Table 2 Free T4 levels between groups

\begin{tabular}{|l|l|l|l|l|}
\hline Characteristics & \multirow{n}{*}{$\boldsymbol{l}$} & \multicolumn{2}{|l|}{ Free T4 } & \multirow{2}{*}{-value } \\
\cline { 3 - 5 } & & Mean & SD & \\
\hline Histopathology & \multicolumn{5}{|l}{} \\
\hline Malignant & 40 & 0.97 & 0.17 & \\
\hline Benign & 40 & 1.19 & 0.19 & \\
\hline
\end{tabular}

Abbreviation: SD, standard deviation.

${ }^{*}$ statistically significant, $p<0.05$.

There was a statistically significant difference for the mean fT4 levels between groups ( $p=0.001$ ).

Female cases had lower mean TSH levels than their matched controls, whereas male cases had higher mean TSH levels than their matched controls. None of these differences were statistically significant. This study observed no significantly higher mean levels of TSH among female cases as compared with female controls, but TSH levels were similar between cases and controls among men. Serum TSH levels below the normal range were associated with an elevated risk of PTC among women, but not among men. Thyroid stimulating hormone levels above the normal range were only associated with an increased risk of PTC among men. There was an inverse association between PTC and TSH levels within the normal range among both men and women. The observed associations varied somewhat by histologic subtypes (classical versus follicular variant PTCs) and by tumor size ( $\leq 10$ versus $>10 \mathrm{~mm}$ ) among men and women. The gender effect on the association between TSH and PTC was only observed among classical PTC cases. Thyroid stimulating hormone levels showed a stronger association with PTC with larger tumor sizes. ${ }^{22}$

The youngest subject was 17 years old, while the oldest was 71 years old, and the average age was 44.5 years old. Age frequencies $\geq 45$ years old included $48(60.0 \%)$ patients, and $<45$ years old included $32(40 \%)$ patients ( - Table 3 ). Based on the $x^{2}$ test, there were no significant differences in TSH levels between ages between groups $(p=0.927)$.

Table 3 Thyroid stimulating hormone levels and clinical characteristics of patients with thyroid enlargement

\begin{tabular}{|c|c|c|c|c|}
\hline $\begin{array}{l}\text { Subject } \\
\text { characteristics }\end{array}$ & $n$ & $\begin{array}{l}\text { High TSH } \\
n(\%)\end{array}$ & $\begin{array}{l}\text { Low TSH } \\
n(\%)\end{array}$ & p-value \\
\hline \multicolumn{5}{|l|}{ Gender } \\
\hline Male & 20 & $12(33.3)$ & $8(12.4)$ & \multirow[t]{2}{*}{0.095} \\
\hline Female & 60 & $24(66.7)$ & $38(87.6)$ & \\
\hline \multicolumn{5}{|l|}{ Age } \\
\hline$<45$ years old & 32 & 15 (46.9) & $17(42.5)$ & \multirow[t]{2}{*}{0.927} \\
\hline$\geq 45$ years old & 48 & $22(53.1)$ & $26(57.5)$ & \\
\hline \multicolumn{5}{|l|}{ Nodule } \\
\hline Uninodular & 49 & $32(65.3)$ & $17(34.7)$ & \multirow[t]{2}{*}{$0.02^{*}$} \\
\hline Multinodular & 31 & $9(29.1)$ & $22(70.9)$ & \\
\hline
\end{tabular}

Abbreviation: TSH, thyroid stimulating hormone.

${ }^{*}$ statistically significant, $p<0.05$.
Another study found that most PTCs originate in infancy and in childhood, based on the early rise in sporadic thyroid carcinoma incidence. ${ }^{9,20}$

The mean difference in this hospital population-based study for fT4 levels between malignant and benign groups was tested with independent sample t-tests (-Table 2). There was a significant difference for the mean fT4 levels between groups ( $p=0.001$ ).

The present study obtained results showing 49 (61.3\%) uninodular and 31 (38.7\%) multinodular (-Table 3). This difference is statistically significantly different $(p=0.02)$. Another study reported that $60 \%$ of the patients with thyroid enlargement were uninodular, $40 \%$ of the patients were multinodular, and $61 \%$ of the patients in the malignancy group were uninodular $(p=0.02){ }^{23}$ Another community populationbased study with 865 subjects reported that there were 53\% uninodular patients, $47 \%$ multinodular, and that $51 \%$ of the patients in the malignancy group were uninodular $(p<0.002) .{ }^{24}$ In patients with nodular thyroid disease, the risk of thyroid malignancy increases with serum TSH, and even within normal ranges, higher TSH values are associated with a higher frequency and with a more advanced stage of thyroid cancer. The likelihood of PTC is reduced when TSH is lower, as in thyroid autonomy, and increased when TSH is higher, as in thyroid autoimmunity. ${ }^{6,9,24}$

Thyroid nodules are $\sim 4$ times more common in women than in men. Palpable nodules increase in frequency throughout life, reaching a prevalence of $\sim 5 \%$ in the population of the United States aged $\geq 50$ years old. Nodules are even more prevalent when the thyroid gland is examined at autopsy or surgery, or when using ultrasonography, and 50\% of these have nodules, which are almost always benign. New nodules develop at a rate of $\sim 0.1 \%$ per year, beginning in early life, but at a much higher rate $(\sim 2 \%$ per year $)$ after exposure to head and neck irradiation. ${ }^{24}$

Papillary thyroid cancer is the most common type of differentiated thyroid cancer. Many subtypes of PTC have been described, and follicular variant papillary thyroid cancer (FVPTC) is a common subtype that is found in between 23 and $41 \%$ of the patients with PTC. Follicular variant papillary thyroid cancer is defined by the presence of tumor cells arranged almost entirely in a follicular architectural pattern, with nuclear features identical to those of conventional PTC. It has also been hypothesized that FVPTC behaves clinically in a way that is similar to conventional PTC..$^{20,25,26}$

One community population-based study consisted of 741 (341 female, 400 male) histologically-confirmed PTC cases and of 741 matched controls. Compared with the middle tertile of TSH levels within the normal range, serum TSH levels below the normal range were associated with an elevated risk of PTC among women (odds ratio $[\mathrm{OR}]=3.74$; 95\% confidence interval [CI]: 1.53-9.19), but not among men. Thyroid stimulating hormone levels above the normal range were associated with an increased risk of PTC among men ( $\mathrm{OR}=1.96 ; 95 \% \mathrm{Cl}: 1.04-3.66)$, but not among women. The risk of PTC decreased with increasing TSH levels within the normal range among both men and women. ${ }^{22}$ 
In this hospital population-based study, the mean difference for nodule size between groups was tested with independent sample t-tests. There was no significant difference for the mean nodule size between groups $(p=0.148)$. The mean nodule size was $5.12 \pm 3.89 \mathrm{~mm}$ in the group with benign thyroid enlargement, and $3.78 \pm 2.32 \mathrm{~mm}$ in the group with thyroid malignancy, and there was no significant difference between groups ( $p=0.065)$. A community population-based study with 483 subjects found the same result. $^{23}$

- Table 3 shows that there was no significant difference in the mean TSH levels between age $(p=0.927)$ and gender $(p=0.095)$, but there were significant differences in the mean TSH levels between uninodular and multinodular $(p=0.01)$. Another study obtained similar results, in which there were no significant differences in the mean TSH levels between age $(p=0.17)$ and gender $(p=0.74){ }^{23}$

A community population-based study about the relationship between fT4 levels and thyroid malignancy in 483 subjects found some different results. The mean fT4 level was $1.25 \pm 0.01 \mathrm{ng} / \mathrm{dl}$ in the group with benign thyroid enlargement, and $1.26 \pm 0.04 \mathrm{ng} / \mathrm{dl}$ in the group with thyroid malignancy, but there was no significant difference between groups $(p=0.784) .^{23}$

Another community population-based study conducted with 441 subjects found that not all ranges of fT4 levels have a significant correlation with thyroid malignancy. There was a significant association in the range between 0.85 and 1.17 ng/dL fT4 levels $(p<0.05)$, but there was no significant association in all ranges of fT4 levels with the incidence of thyroid malignancies. Several studies on the relationship of fT4 and thyroid malignancy show varying results. ${ }^{27}$

The aforementioned study reported variables that had a role for thyroid malignancy using multivariate analysis. Variables were nodule characteristics, TSH level, free T3 level, and fT4 level. The study did not determine any correlation between TSH levels and nodule characteristics. The conclusion of that study found that TSH level was an independent risk factor for thyroid malignancy separate from nodule characteristics. ${ }^{27}$

In this hospital population-based study, the mean difference for TSH levels between groups was tested with independent sample t-tests. - Table 4 shows that there was a significant difference for the mean TSH level between both malignant and benign groups $(p=0.001)$. Based on the classification of high and low TSH levels, there was a statistically significant difference between the malignant and benign groups ( $p=0.001 ; \mathrm{OR}=8.42 ; 95 \% \mathrm{CI}$ : 3.19-36.5) Patients with high TSH levels have an 8.42 times higher risk of developing malignant tumors (differentiated thyroid carcinoma) than patients with low TSH levels.

Many factors can influence free T4 levels, including TSH levels in the human body. Free T4 is considered not reliable to determine thyroid malignancy due to the many factors that can affect its level (for example, protein serum), and there has not been a clearly determined role in thyroid oncogenesis. ${ }^{28}$

Ongoing TSH stimulation can change slowly differentiated thyroid carcinoma into malignancies that grow rapidly and metastasize. Increased levels of TSH will increase the growth of thyroid carcinoma. ${ }^{29,30}$

Differentiated thyroid tumors express TSHR in the plasma membrane. Thyroid stimulating hormone will increase adenylate cyclase activity, which also increases cAMP production and cell growth through TSHR on in vitro examination. Thyroid carcinomas are still affected by TSH, so TSH suppression performed by administering thyroxine in oral suppression doses can control the progression of thyroid carcinoma, as well as recurrence of patients receiving surgical therapy and radioactive iodine. ${ }^{30,31}$

Investigations performed according to the guidelines of the UK Association of Thyroid Cancer (United Kingdom), are advised to perform Thyroid Function Tests (TFTs) first in patients with thyroid nodules. The results of these checks are used to determine the intended referrals. If the euthyroid with suspected thyroid nodules are malignant, then the patients are referred to the cancer handling team. A hypothyroid and hyperthyroid state is not necessarily a malignancy, as differentiated cancer cells also have the ability to capture iodine and produce thyroglobulin. In some cases, differentiated thyroid cancers have been reported with thyrotoxic conditions. $^{32,33}$

The incidence of malignancy is higher along with elevated serum TSH levels, giving an overview of the tropic effect of $\mathrm{TSH}$ on thyroid tissue carcinogenesis. Iodine deficiency causes a decrease in thyroid hormone levels that will increase serum TSH levels. Chronic iodine deficiency has been recognized as a risk factor for the growth of FTC. ${ }^{34,35}$

Plenty of evidence suggests that serum TSH levels are an independent predictor for the diagnosis of thyroid malignancies in patients with thyroid gland enlargement. Preoperative TSH levels were also higher in patients with more aggressive tumors. $^{36,37}$

Based on these facts, patients with higher TSH levels and dubious cytology findings require more complete

Table 4 Thyroid stimulating hormone level analysis between groups

\begin{tabular}{|c|c|c|c|c|c|}
\hline \multirow[t]{2}{*}{ Laboratory result } & \multicolumn{2}{|c|}{ Histopathology } & \multirow[t]{2}{*}{$n$} & \multirow[t]{2}{*}{ p-value } & \multirow[t]{2}{*}{ OR $(95 \% \mathrm{Cl})$} \\
\hline & Malignant & Benign & & & \\
\hline TSH Level & $1.24 \pm 0.71$ & $0.56 \pm 0.31$ & \multicolumn{2}{|l|}{$0.001^{*}$} & \\
\hline High TSH & $26(65)$ & $6(15)$ & $32(40)$ & \multirow[t]{2}{*}{$0.001^{*}$} & \multirow[t]{2}{*}{$8.42(3.19-36.50)$} \\
\hline Low TSH & $14(35)$ & $34(85)$ & $48(60)$ & & \\
\hline
\end{tabular}

Abbreviations: $\mathrm{Cl}$, confidence interval; OR, odds ratio; TSH, thyroid stimulating hormone.

* statistically significant, $p<0.05$. 
examination than patients with lower TSH levels. The normal state of thyroid function that is not affected by TSH levels is called the autonomic thyroid function (TSH $<0.4 \mu \mathrm{IU} / \mathrm{ml}$ ), and is associated with a reduced risk of PTC. A number of studies support conclusions that higher levels of TSH, although still within the normal range, are associated with thyroid cancer in patients with thyroid gland enlargement. ${ }^{10,20,33,38}$

\section{Conclusion}

There were statistically significant differences in TSH levels between differentiated thyroid carcinoma and benign thyroid enlargement in the present hospital population-based study. Patients with high TSH levels have a significantly higher risk of differentiated carcinoma than patients with low TSH levels. Multicenter hospital population-based studies need to be conducted for the generalization of these findings linking the differences in TSH levels between differentiated thyroid carcinoma and benign thyroid enlargement.

Conflicts of Interests

The authors have no conflicts of interests to declare.

\section{References}

1 Cinamon U, Levy D, Marom T. Is primary hyperparathyroidism a risk factor for papillary thyroid cancer? An exemplar study and literature review. Int Arch Otorhinolaryngol 2015;19(01):42-45

2 Haugen BR, Alexander EK, Bible KC, et al. 2015 American Thyroid Association Management Guidelines for Adult Patients with Thyroid Nodules and Differentiated Thyroid Cancer: The American Thyroid Association Guidelines Task Force on Thyroid Nodules and Differentiated Thyroid Cancer. Thyroid 2016;26 (01):1-133

3 Polyzos SA, Kita M, Efstathiadou Z, et al. Serum thyrotropin concentration as a biochemical predictor of thyroid malignancy in patients presenting with thyroid nodules. J Cancer Res Clin Oncol 2008;134(09):953-960

4 Tuncel M. Thyroid stimulating hormone receptor. Mol Imaging Radionucl Ther 2017;26(Suppl 1):87-91

5 Khan MS, Pandith AA, Masoodi SR, Wani KA, Ul Hussain M, Mudassar S. Epigenetic silencing of TSHR gene in thyroid cancer patients in relation to their BRAF V600E mutation status. Endocrine 2014;47(02):449-455

6 Fiore E, Vitti P. Serum TSH and risk of papillary thyroid cancer in nodular thyroid disease. J Clin Endocrinol Metab 2012;97(04): 1134-1145

7 Ramli NSF, Mat Junit S, Leong NK, Razali N, Jayapalan JJ, Abdul Aziz A. Analyses of antioxidant status and nucleotide alterations in genes encoding antioxidant enzymes in patients with benign and malignant thyroid disorders. PeerJ 2017;5:e3365

8 Dirikoç A, Fakı S, Başer $\mathrm{H}$, et al. Thyroid malignancy risk in different clinical thyroid diseases. Turk J Med Sci 2017;47(05): 1509-1519

9 Williams D. Thyroid growth and cancer. Eur Thyroid J 2015;4(03): 164-173

10 Sulaieva O, Chernenko O. Correlations between TSH level and morphological features of thyroid tumours. P2-03-82. Eur Thyroid J 2017;6(Suppl 1):23-118

11 Podda M, Saba A, Porru F, Reccia I, Pisanu A. Follicular thyroid carcinoma: differences in clinical relevance between minimally invasive and widely invasive tumors. World J Surg Oncol 2015;13 (193):193
12 Carney HC, Ward CR, Bailey SJ, et al. 2016 AAFP Guidelines for the Management of Feline Hyperthyroidism. J Feline Med Surg 2016; 18(05):400-416

13 Golbert L, de Cristo AP, Faccin CS, et al. Serum TSH levels as a predictor of malignancy in thyroid nodules: A prospective study. PLoS One 2017;12(11):e0188123

14 Le KT, Sawicki MP, Wang MB, Hershman JM, Leung AM. High prevalence of agent orange exposure among thyroid cancer patients in the national VA healthcare system. Endocr Pract 2016;22(06):699-702

15 Haymart MR, Repplinger DJ, Leverson GE, et al. Higher serum thyroid stimulating hormone level in thyroid nodule patients is associated with greater risks of differentiated thyroid cancer and advanced tumor stage. J Clin Endocrinol Metab 2008;93(03): 809-814

16 Khan MA, Malik N, Khan KH, Shahzad MF. Association of preoperative serum thyroid-stimulating hormone levels with thyroid cancer in patients with nodular thyroid disease. World J Nucl Med 2017;16(03):202-205

17 Pourhoseingholi MA, Vahedi M, Rahimzadeh M. Sample size calculation in medical studies. Gastroenterol Hepatol Bed Bench 2013;6(01):14-17

18 Ma Y, Zhang X, Wang Y. Reactivity of thyroid papillary carcinoma cells to thyroid stimulating hormone-dominated endocrine therapy. Oncol Lett 2017;14(06):7405-7409

19 Lee I-S, Hsieh A-T, Lee T-W, Lee T-I, Chien Y-M. The association of thyrotropin and autoimmune thyroid disease in developing papillary thyroid cancer. Int J Endocrinol 2017; $\cdots: 1-8$

20 Gill KS, Tassone P, Hamilton J, et al. Thyroid cancer metabolism: a review. J Thyroid Disord Ther 2016;5(01):1-7

21 Mussa A, De Andrea M, Motta M, Mormile A, Palestini N, Corrias A. Predictors of malignancy in children with thyroid nodules. J Pediatr 2015;167(04):886-892.e1

22 Huang H, Rusiecki J, Zhao N, et al. Thyroid-stimulating hormone, thyroid hormones, and risk of papillary thyroid cancer: a nested case-control study. Cancer Epidemiol Biomarkers Prev 2017;26 (08):1209-1218

23 Moon SS, Lee YS, Lee IK, Kim JG. Serum thyrotropin as a risk factor for thyroid malignancy in euthyroid subjects with thyroid micronodule. Head Neck 2012;34(07):949-952

24 Cooper DS, Doherty GM, Haugen BR, et al; American Thyroid Association Guidelines Taskforce. Management guidelines for patients with thyroid nodules and differentiated thyroid cancer. Thyroid 2006;16(02):109-142

25 Tuttle RM, Ball DW, Byrd D, et al; National Comprehensive Cancer Network. Thyroid carcinoma. J Natl Compr Canc Netw 2010;8 (11):1228-1274

26 Kim YJ, Lee KA, Park TS, Baek HS, Jin HY. Multiple metastasis of follicular variant of papillary thyroid carcinoma coexistent with malignant melanoma. Korean J Intern Med (Korean Assoc Intern Med) 2018;33(03):634-637

27 Soh EY, Sobhi SA, Wong MG, et al. Thyroid-stimulating hormone promotes the secretion of vascular endothelial growth factor in thyroid cancer cell lines. Surgery 1996;120(06):944-947

28 Boelaert K. The association between serum TSH concentration and thyroid cancer. Endocr Relat Cancer 2009;16(04):1065-1072

29 Pujol P, Daures J-P, Nsakala N, Baldet L, Bringer J, Jaffiol C. Degree of thyrotropin suppression as a prognostic determinant in differentiated thyroid cancer. J Clin Endocrinol Metab 1996;81(12): 4318-4323

30 Beasley MJ. Lymphoma of the thyroid and head and neck. Clin Oncol (R Coll Radiol) 2012;24(05):345-351

31 Gul K, Ozdemir D, Dirikoc A, et al. Are endogenously lower serum thyroid hormones new predictors for thyroid malignancy in addition to higher serum thyrotropin? Endocrine 2010;37(02):253-260

32 Tuttle RM, Lemar H, Burch HB. Clinical features associated with an increased risk of thyroid malignancy in patients with follicular neoplasia by fine-needle aspiration. Thyroid 1998;8(05):377-383 
33 Lin Jen-Der, Lin Shu-Fu, Chen Szu-Tah, Hsueh C, Li Chia-Lin, Chao Tzu-Chieh. Long-term follow-up of papillary and follicular thyroid carcinomas with bone metastasis. PLoS One 2017;9:1-11

34 Lamartina L, Grani G, Durante C, Filetti S. Recent advances in managing differentiated thyroid cancer. F1000Res.ecollection 2018;7:1-10

35 Deirdre K, Catherine MK. Clinical overview of thyroid cancer and recent advances in treatment. J Oncol Med \& Pract. 2016;1(02): $1-6$
36 Dean DS, Hay ID. Prognostic indicators in differentiated thyroid carcinoma. Cancer Contr 2000;7(03):229-239

37 Mitchell AL, Gandhi A, Scott-Coombes D, Perros P. Management of thyroid cancer: United Kingdom National Multidisciplinary Guidelines. J Laryngol Otol 2016;130(S2):S150-S160

38 Frates MC, Benson CB, Doubilet PM, et al. Prevalence and distribution of carcinoma in patients with solitary and multiple thyroid nodules on sonography. J Clin Endocrinol Metab 2006;91 (09):3411-3417 